Double identification of sentinel lymph
node with indocyanine green and $99 \mathrm{~m}$ -
technetium in vulvar cancer and V-Y flap for
vulvar reconstruction

Daniel Vázquez-Vicente (D) , ${ }^{1}$ Francisco Campillo, ${ }^{1}$ Felix Boria (D) , ${ }^{1}$ Teresa Castellanos, ${ }^{1}$ E F Guillen, ${ }^{2}$ Luis Chiva (iD ${ }^{1}$

${ }^{1}$ Obstetrics and Gynecology, Clinica Universidad de Navarra, Madrid, Spain

${ }^{2}$ Nuclear Medicine, Clínica Universidad de Navarra, Madrid, Madrid

\section{Correspondence to} Dr Daniel Vázquez-Vicente, Gynecology, Clinica Universidad de Navarra, Madrid, Spain; dvazquezv@unav.es

Accepted 3 November 2020 Published Online First 23 November 2020
In this video we show the different steps in the approach to a case of vulvar cancer from the first consultation to final treatment. The surgical procedure involved the double location of a sentinel lymph node with indocyanine green (ICG) and with 99m-technetium, followed by vulvectomy and flap reconstruction.

A 43-year-old woman without a relevant past medical history and with no previous sexual relations was referred to us for a second opinion due to a 3 $\mathrm{cm}$ vulvar lesion in the left upper third major labia. Despite her age, an extensive area suspicious of lichen sclerosus was presented all over the vulva.

Initial biopsy showed a squamous cervical carcinoma, so we followed the study by vulvar mapping to exclude more invasive carcinoma, which confirmed the extensive lichen sclerosus without local metastases. We confirmed the absence of distant metastases with positron emission tomography-computed tomography and also the metabolic activity of the vulvar tumor.

In this video the following procedures are shown, highlighting the different steps:

- Double location of left sentinel lymph node, first with the $99 \mathrm{~m}$-technetium detector followed by ICG identification. We used an ICG dilution of 2.5 $\mathrm{mg} / \mathrm{mL}$ in sterile water and injected $4 \mathrm{~mL}$ around the tumor 15 min before visualization.

- Simple right vulvectomy and radical left vulvectomy.

- Modified vulvar reconstruction with $V-Y$ technique.

Intra-operative analysis of the sentinel lymph node showed it was free of disease so no further treatment was necessary. The final pathological report showed $1 \mathrm{~cm}$ of squamous carcinoma with all margins free of disease (International Federation of Gynecology and

\title{
GYRECTIONAL JOURNAL OF
}

Double identification of sentinel lymph node with Indocyanine Green and Technetium-99m in

(D) Check for updates

(C) IGCS and ESGO 2021. No commercial re-use. See rights and permissions. Published by BMJ.

\footnotetext{
To cite: Vázquez-Vicente $D$, Campillo F, Boria F, et al. Int $J$ Gynecol Cancer 2021;31:300301.
}

Vazquez-Vicente D, Campillo F, Boria F, Castellanos T, Guillen F, Chiva L

\section{vulvar cancer and V-Y flap for vulvar reconstruction}

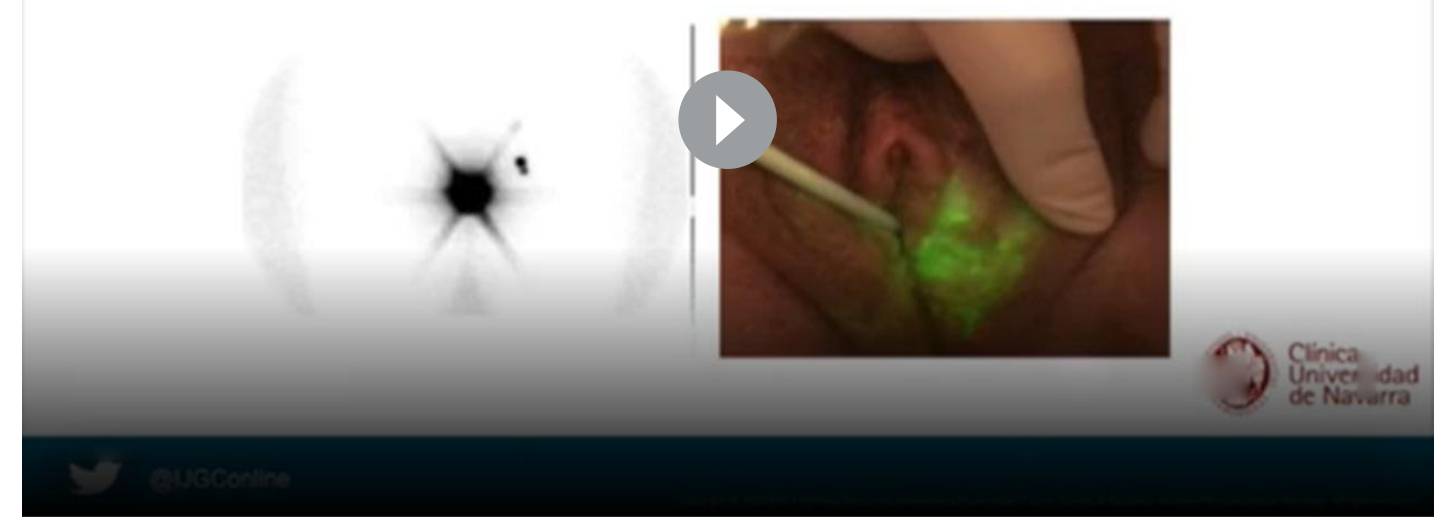

Video 1 Technetium-99 imaging study and ICG vulvar visualization. 
Obstetrics 2018 stage IB). The rest of the resected vulva showed lichen sclerosus. The patient was discharged 4 days after surgery without any complications.

The approach to vulvar cancer needs to balance the aggressiveness and morbidity of the intervention, especially lymphadenectomy which requires a long post-operative period. Because of this, application of a reliable sentinel node technique is of utmost importance.

Using ICG in addition to 99m-technetium may help to increase the detection of the vulvar sentinel node. ${ }^{1}$ Performing a vulvar flap can help decrease wound dehiscence. ${ }^{2}$

Twitter Felix Boria @BoriaFelix

Contributors All the authors contributed to the creation of the article.

Funding The authors have not declared a specific grant for this research from any funding agency in the public, commercial or not-for-profit sectors.

Competing interests None declared.
Patient consent for publication Not required.

Provenance and peer review Not commissioned; externally peer reviewed.

Data availability statement All data relevant to the study are included in the article.

\section{ORCID iDs}

Daniel Vázquez-Vicente http://orcid.org/0000-0002-9618-5606

Felix Boria http://orcid.org/0000-0002-4761-6190

Luis Chiva http://orcid.org/0000-0002-1908-3251

\section{REFERENCES}

1 Broach V, Abu-Rustum NR, Sonoda Y, et al. Evolution and outcomes of sentinel lymph node mapping in vulvar cancer. Int $J$ Gynecol Cancer 2020;30:383-6.

2 Hand LC, Maas TM, Baka N, et al. Utilizing V-Y fasciocutaneous advancement flaps for vulvar reconstruction. Gynecol Oncol Rep 2018;26:24-8. 